\title{
Revolving doors: entrepreneurial survival and exit
}

\author{
Elena Cefis • Orietta Marsili
}

Published online: 12 February 2011

(C) The Author(s) 2011. This article is published with open access at Springerlink.com

\begin{abstract}
The high turbulence of new entrepreneurial ventures that are rapidly selected out at the fringe of the firm population has been emphasized using the "revolving doors" metaphor. However, well-planned exit strategies can be the root of entrepreneurial success and a mechanism to transfer novelty to established firms. The aim of this Special Issue is to highlight the multiple aspects of exit as part of the entrepreneurial process.
\end{abstract}

Keywords Firm exit • Exit route • Entrepreneurship •

Selection and growth dynamics $\cdot$ Credit rating

JEL Classification D20 • G33 • G34 • J24 • L22 • L25 • L26 • M13

\section{Introduction}

Entrepreneurial ventures are subject to great risk of failure, often exiting the market soon after they startup. Industrial economists have referred to these short-lived firms using the "revolving doors" metaphor (Audretsch 1995). This

E. Cefis $(\varangle)$

Dep. of Economics, University of Bergamo, via dei Caniana 2, 24124 Bergamo, Italy

e-mail: elena.cefis@unibg.it

E. Cefis

T.C.Koopmans Research Institute, USE, Utrecht University, Janskerkhof 3,

3512 BL Utrecht, The Netherlands

O. Marsili

Rotterdam School of Management, Erasmus University, Postbus 1738, 3000 DR Rotterdam, The Netherlands

e-mail: omarsili@rsm.nl 
to emphasize the high turbulence of new ventures that are rapidly selected out at the fringe of the firm population, in contrast to high potential new firms that are able to survive and displace established firms (according to the metaphor of the forest), and which provide a long-term contribution to job creation and economic wealth. What the metaphor did not seem to capture is that wellplanned exit strategies can be the root of entrepreneurial success. Studies in the entrepreneurship literature have started to consider exit as an integral part of the entrepreneurial processes, a stage in the life cycle of new ventures and a step in the career path of the founders, which need to be carefully prepared for (DeTienne 2010). Short-lived new ventures can also assume a role in the context of the growth strategies of established firms. Large firms can 'eat up' novelty by acquiring innovative new firms that lack the resources necessary to exploit what they know. Entrepreneurial exit thus becomes a mechanism to transfer novelty to established firms. Although selection may rapidly force new ventures out of the market, "revolving doors" firms can represent a vital place of experimentation in the innovation ecosystem. In this respect, survival may not be the necessary purpose of an organization, or the optimal outcome of market competitive forces. As the management literature suggests, exit can be a sign of success and a critical element of the overall strategy of a firm (Decker and Mellewigt 2007).

The very recent scientific research has come to address firm exit from different perspectives, drawing attention to the many different factors that influence exit, and the topic has become to be very discussed in the field. These considerations encouraged us to organize a workshop with the title "Revolving doors: Entrepreneurial survival and exit", which was held at the Rotterdam School of Management, in November 2008. The aim of the workshop and of this Special Issue was to highlight the multiple aspects of exit as part of the entrepreneurial process. Three main themes emerged from the presentations and the discussion during the workshop and the Special Issue has been organized around them. Section 2 elaborates the theme on exit and firm's performance. Section 3 presents the papers that investigate the value or the benefits of the exit and Section 4 those regarding the influence of the external environment on firm exit. The last Section concludes with general implications derived from the overall collection of papers.

\section{Exit and performance}

One theme, developed in this Special Issue, is the relationship between exit and performance. Exit is generally considered a sign of failure of the firm, a consequence of poor performance: firms that underperform as they compete in the market will, sooner or later, exit the market (Gimeno et al. 1997; Nelson and Winter 1982). Two papers look at firms in distress and their exit behavior: the paper by Bottazzi, Grazzi, Secchi, and Tamagni, focusing on the implications of different types of signals of distress and the paper by Balcaen, 
Manigart, and Ooghe, looking at the time elapsing between distress and the actual exit.

At the center of the paper Financial and Economic Determinants of Firm Default by Bottazzi, Grazzi, Secchi, and Tamagni is the consideration that poor performance can assume different meanings, and be signaled by different indicators. While industrial economists emphasize asymmetries in growth, profitability and productivity, for financial economists these dimensions are fully reflected into a firm's accounting books, and do not call for additional attention. The study compares the past performance of defaulting firms by a large Italian bank with non-defaulting firms, showing that both financial and economic dimensions of performance matter to predict exit. However these effects are more persistent over time for financial performance than for economic performance: firms may recover (and avoid exit) from a situation of distress if this means poor figures in sales or growth, while such a reverse of fortune is less likely to occur when the firm bears an unbalanced capital structure or heavy costs of debt. The authors conclude that because of imperfections in the capital markets, any attempt to predict firm failure requires an assessment of the firm past economic performance and cannot be based exclusively on its financial ratings.

The second paper, From Distress to Exit: Determinants of the Time to Exit by Balcaen, Manigart, and Ooghe shows that even when exit is the likely outcome of a situation of distress, how fast to run to the exit door is still a matter of choice for the firm. It depends on the type of exit and organizational factors like firm's slack resources and stakeholders dependence. When a firm is in distress the entrepreneur or the management can decide to liquidate the company and cash on the assets still at its disposal, or rather wait until being forced to declare bankruptcy, with the undesirable outcome of a negative fallout on the reputation of the management and the ownership. Using a sample of distress related exits among Belgian Small and Medium Enterprises (SME) the authors find that slack resources that are presently available to the firm increase flexibility in timing the exit. When firms in distress can still relay on cash flow they are in better conditions to delay bankruptcy, as well as to accelerate liquidation, if they choose to do so. Potential (rather than available) slack resources, calling for more future debt, do not have a similar effect. Furthermore, entrenched relationships with stakeholders may lead to inertia and increased costs in the process of exit, slowing down both bankruptcy and voluntary liquidation.

\section{The benefits of exit}

The second theme is about the value or benefits of exit. Within this theme, Hessels, Grilo, Thurik and van der Zwam examine the benefits at the level of the individual and see exit as one step in the career path of the entrepreneur. Cefis and Marsili look at the benefits at the level of the firm, for which exit 
can represent a mean to gain economic returns from entrepreneurial activity, alternative to competing in the market.

In the first paper, Entrepreneurial Exit and Entrepreneurial Engagement, Hessels et al. take the entrepreneur as the center of analysis, the decision maker in the process of exit. In doing so, they provide some micro-foundation to patterns of exit that are observed at aggregate level. Past exits as driver of industry evolution enhance the level of new firm formation in regions, or the economy as they release resources that become available to entrepreneurs, and can be employed in more efficient ways. This paper indicates that a similar mechanism of path dependence, or learning by failure, is present at the individual level. Based on data from the Global Entrepreneurship Monitor (GEM), the authors find that individuals who have terminated a past entrepreneurial experience (closing down the company they owned or managed in the previous year) are more likely to engage in future entrepreneurial activity. This occurs at various degrees of engagement, ranging from being again a potential entrepreneur to owing another, new or established business. The individuals who re-engage in entrepreneurial activity have less 'fear of failure', but also a broader entrepreneurial social capital, in the sense that they know other entrepreneurs or have previously invested in the new ventures of other entrepreneurs.

The second paper in this theme, Exit Decisions of Entrepreneurial Firms in High-tech and Low-tech industries by Cefis and Marsili, focuses on exit as strategy for the firm to extract economic rents from innovation. New firms often distinguish themselves for their ability to innovate. Innovation generates entrepreneurial rents by enhancing the firm competitive advantage as well as by increasing the company value in a possible merger or acquisition (M\&A), where the resources and capabilities of the innovator are (to a certain extent) transferred to other firms. Based on a comparison of exit behavior between young and established Dutch manufacturing firms, this study shows that innovation plays a significant role in shaping the exit strategy of entrepreneurial firms, and its effect is contingent on the nature of the technology environment. In low-tech industries, but not in high-tech industries, by innovating new firms are assured better options with respect to the decision to stay in the market (as they are able to avoid closure) or to sell out (as they become attractive target of a M\&A). In high-tech industries by innovating, new firms gain only access to a fast pace race with incumbents, with is no guarantee of success.

\section{External influences on firm's exit}

The third theme is about the influence on firm's exit of the external environment. A key question in industrial economics is whether the dynamics of entries and exits in industrial sectors display some general properties - a path of their own-or are rather influenced by external conditions. Carree, Santarelli, and Verheul take a broad look on entrepreneurial exit, as a driver 
of industry evolution. Ebersberger addresses the question of whether public policies seeking to support corporate innovation can effectively lower exit.

The paper Sectoral Patterns of Firm Exit in Italian Provinces by Carree, Santarelli, and Verheul examines the conditions that at level of industries and regions influence exit dynamics, in the context of Italian industrial districts. The study provides further support for the existence of a positive relationship between entries and exits, as a general property of firm dynamics. This is the outcome of two effects. A "revolving door" effect when exiting firms are the same that have entered the market not long before, leaving the heart of the population largely unaffected. And a "displacement effect" when exits take place among existing firms that are forced out by new entrants. Industries evolve through a process of creative destruction where new firms are able to threaten the very existence of established firms (Schumpeter 1934). In addition, the paper brings to light another mechanism, a "domino effect", in firm dynamics. Exits spill over across connected industries, and high exits in one sector will lead to high exits in other sectors. These effects differ across sectors-the 'domino effect' is typical of service industries, while the displacement effect is dominant in manufacturing. Furthermore, the effects are more pronounced across sectors than differences due to regional conditions. The results suggest that to explain exits, although location matters it is essential to account, not only for industry-specific conditions, but also for the system of interdependence that link related industries.

The paper Public Funding for Innovation and the Exit of the Firms by Ebersberger examines whether the granting of an innovation subsidy by the Finnish National Funding Agency for Innovation and Technology (responsible for $85 \%$ of public funding for corporate innovation) was able to lower the risk of firms exiting by closure and by merger. By matching the set of subsidized firms with non-subsidized firms of similar characteristics, the study compares the exit probability of subsidized firms with the counterfactual exit probability that these same companies would have had if they had not received the subsidy. The study finds that innovation subsidies lower exit probability by merger, but have no effect on exit by closure, suggesting that public support to innovation unfold through different mechanisms when it comes to different modes of exit. While exit by closure is highly dependent on the immediate availability of cash flow, exit by merger depends also on the ability of a firm to leverage future funding and to further invest in innovation. Thus, the evidence from this study does not support the argument that public funding allows financially constrained firms to survive longer than they would normally do. There is instead support for the existence of an enduring effect of public subsidies on the innovative efforts of firms, which lower the probability to exit by a merger.

\section{Implications}

When looking at the papers collected in this Special Issue as a whole, they contribute to our general understanding of entrepreneurial exit in three directions. 
First, the papers show the importance of a definition of exit that distinguishes the various forms of exit. Firm default, voluntary liquidation, court-based exit, and exit by M\&A assume different meanings in terms of the success or failure of firms and entrepreneurs, and respond to different motivations and determinants. It also becomes apparent that a more nuanced definition of exit demands more attention to strategic considerations about exit, at the level of both the organization and the individual entrepreneur. Second, the papers highlight the dynamic nature of exit. Exits are path dependent and influence future decisions of entrepreneurs. In an organization, exit is a process that takes time and unfolds through successive phases. It can begin with a signal of distress and go though a more or less well-defined sequence of events until the firm is completely dissolved. However, the process can be reverted, slowed down or even accelerated, depending on the choice and capabilities of the firm. Finally, the collection of papers illustrates how exit involves several levels of analysis and is influenced by multiple factors. These effects appear to be non-linear (for example, due to the interplay between firm strategies and the external environment) and are specific to the form of exit considered.

Acknowledgements The Guest Editors would like to thank Uwe Cantner and Luigi Orsenigo for their support throughout the organization and publication of this Special Issue. Also, many thanks to the 14 referees that collaborate with us for their valuable suggestions and contributions. Finally, we would like to thank the Centre for Entrepreneurship \& New Business Venturing and ERIM of the Rotterdam School of Management that, to celebrate the fifth anniversary of the Centre, organized and financed the workshop. Elena Cefis acknowledges the financial supports of the Utrecht University [High Potential Grant (HIPO)]; and the University of Bergamo [grant ex $60 \%$, n. 60CEFI10, Dept. of Economics].

Open Access This article is distributed under the terms of the Creative Commons Attribution Noncommercial License which permits any noncommercial use, distribution, and reproduction in any medium, provided the original author(s) and source are credited.

\section{References}

Audretsch DB (1995) The propensity to exit and innovation. Rev Ind Organ 10(5):589-605

Decker C, Mellewigt T (2007) Thirty years after Michael E. Porter: what do we know about business exit? Acad Manage Perspect 21:41-55

DeTienne DR (2010) Entrepreneurial exit as a critical component of the entrepreneurial process: Theoretical development. J Bus Venturing 25(2):203-215

Gimeno J, Folta TB, Cooper AC, Woo CY (1997) Survival of the fittest? Entrepreneurial human capital and the persistence of underperforming firms. Adm Sci Q 42(4):750-783

Nelson RR, Winter SG (1982) An evolutionary theory of economic change. Belknap Press of Harvard University Press, Cambridge

Schumpeter JA (1934) The theory of economic development. Harvard Economic Studies, Cambridge 